\title{
ADHD, CREATIVITY, AND METHYLPHENIDATE
}

Creativity, measured by the Torrance nonverbal thinking test, was compared in 19 boys with ADHD and 21 control subjects. Boys with ADHD received methylphenidate (mean dose, $0.4 \mathrm{mg} / \mathrm{kg}$ ) before the first of two test sessions. Torrance scores were $7 \%$ lower in boys with ADHD compared to controls. Methylphenidate did not adversely affect creative thinking scores in ADHD boys. (Funk JB et al. Attention deficit hyperactivity disorder, creativity, and the effects of methylphenidate. Pediatrics April 1993; 91: 816-819). (Reprints: Jeanne B Funk PhD, Dept of Pediatrics, Medical College of Ohio, PO Box 10008, Toledo, OH 43699).

COMMENT. The results suggest that impulsivity, a characteristic of ADHD children, is not fundamental to creativity; and creativity, as measured by the nonverbal Torrance test, is not impaired by methylphenidate.

\section{VISUAL EVENT RELATED POTENTIALS, EEG, AND ADHD}

The effects of methylphenidate (MPH) and sodium valproate (VPA) on the visual event related potentials (VERP) and EEG of children with ADHD were evaluated at the Department of Psychology, Tel Aviv University, Israel, and North Shore University Hospital, Cornell Univ Med College, New York. Two subgroups of ADHD were identified: one with abnormal and the other with normal EEGs and VERPs. The amplitude of the ERP slow negative wave was reduced by MPH and VPA in the abnormal group but was unaffected in the group with normal VERPs. (Frank Y. Visual event related potentials after methylphenidate and sodium valproate in children with attention deficit hyperactivity disorder. Clin EEG Jan 1993; 244:19-24). (Reprints: Yitzchak Frank MD, Div of Pediatric Neurology, North Shore University Hospital, 300 Community Drive, Manhasset, NY 11030).

COMMENT. The effect of medications in ADHD children appears to be related to electrophysiological findings. A positive effect is expected in patients with abnormal EEGs and VERPs.

\section{$\underline{\text { DYSLEXIA }}$}

\section{DYSLEXIA, HANDEDNESS, AND IMMUNE DISORDERS}

An association between dyslexia, left-handedness, and immune disorders was investigated in 734 Norwegian grade 6 children, aged 12 years, at the Center for Reading Research, Stavanger, Norway, and the Department of Psychology, University of Bergen. In the sample studied, $10 \%$ of students were dyslexic, $8 \%$ were left-handed, $35 \%$ had allergic symptoms, and $6 \%$ were asthmatics. $67 \%$ of left-handed dyslexic children had immune disorders $(\mathrm{P}>.05)$; 
$42 \%$ of left-handed children with immune disorders had dyslexia $(\mathrm{P}<.01)$; and $32 \%$ of dyslexic children with immune disorders were left-handed $(\mathrm{P}<.05)$. Of the three factors, handedness was the most important association. (Tonnessen FE et al. Dyslexia, left-handedness, and immune disorders. Arch Neurol April 1993; 50: 411-416). (Reprints: Dr Tonnessen, Center for Reading Research, Box 2504, Ullandhaug, N-4004 Stavanger, Norway).

COMMENT. The Geschwind theory postulates a single factor underlying dyslexia, left-handedness, and immune disorders. The results of this study suggest that left-handedness and dyslexia are more important than immune disorders in a possible three-way association of these conditions.

\section{DYSLEXIA: A VISUAL DISORDER?}

Visual evoked potentials were measured with scalp electrodes in eight reading-disabled children aged 8 to 11 years and compared to a control group of 13 age-matched normal readers at the School of Optometry, University of Missouri, St Louis. Using a steady background and a low-spatial-frequency target ( 0.5 cycle/degree visual angle), the latencies of the early components (N1 and P1) of the VER were longer and the amplitude of the subsequent (P1N2) component was smaller in the reading-disabled than in normal readers. A flickering background increased the latency and reduced the amplitude of the early components of the VER in normal readers, whereas in reading-disabled children only the amplitude was affected. These differences were most likely due to a sensory deficit and slowed response in the magnicellular visual pathway of reading-disabled children. (Lehmkuhle $S$ et al. A defective visual

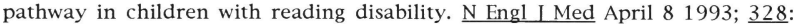
989-996). (Reprints: Stephen Lehmkuhle PhD, School of Optometry, University of Missouri-St Louis, 8001 Natural Bridge Rd, St Louis, MO 63121).

COMMENT. These findings are supported by previous anatomical and electrophysiological studies that have demonstrated a defective magnicellular visual pathway in dyslexic subjects. A cause-and-effect relation between these slowed visual responses and the reading disability remains to be determined.

\section{TOXIC DISORDERS}

\section{COGNITIVE IMPROVEMENT FOLLOWING LEAD CHELATION} The short ( 7 weeks) and long (6 months) term effects of lowered blood" lead levels on cognitive performance were measured in 154 previously untreated lead-poisoned children, aged 13 to 87 months, examined at the Department of Pediatrics, Albert Einstein College of Medicine, Montefiore 